\title{
DE EVANGELISCHE BROEDERGEMEENTE IN SURINAME
}

\author{
DOOR \\ JONKVR. J. W. BARONESSE VAN LYNDEN
}

„Men kan niet genoeg wijzen op hetgeen Suriname uit de handen Uwer Zending heeft ontvangen". Met deze woorden begon de heer F. E. Bruyning, secretaris van het Departement van Financiën in Suriname, zijn toespraak als secretaris van het Zendings-jubileum-comité op de feestelijke bijeenkomst van 23 December 1935 ter herdenking van de twee eeuwen zendingsarbeid der Evangelische Broedergemeente in Suriname.

In een gloedvolle rede ${ }^{1}$ ) zette hij uiteen wat de Zending der Evangelische Broedergemeente voor Suriname is geweest, en zijn rede werd, zooals hij het zelf uitdrukte, ,een getuigen”.

In korte trekken willen wij trachten te schetsen wat Suriname ontvangen heeft door dezen arbeid en een en ander mededeelen van hetgeen daar ook thans nog gedaan wordt.

De Zendingsarbeid, die in 1735 van Herrnhut in Saksen uit werd aangevangen, heeft haar stempel op deze Nederlandsche kolonie gedrukt; de genegenheid voor Nederland en de groote liefde, die het volk van Suriname koestert voor ons Vorstenhuis, is voor een zeer groot deel te danken aan den arbeid der zendelingen.

In de Zondagsche bijeenkomst van de Gemeente wordt in de kerken der Evangelische Broedergemeente gebeden, „dat God Zijn zegen rijkelijk uitstorte over onze geëerbiedigde Koningin en het geheele Koninklijke Huis", gebeden om „leiding en bescherming van onzen Gouverneur en alle ambtenaren des lands, opdat wij onder hen een gerust en stil leven leiden mogen in alle godzaligheid en eerbaarheid".

De herdenkingsdagen van het Koninklijk Huis zijn voor de Surinamers feestdagen, waaraan de geheele bevolking deelneemt, en vooral kwam dit tot uiting bij de geboorte van H. K. H. Prinses Beatrix. Maar in dagen van rouw treurt Suriname ook mede; hoezeer bleek dit bij het overlijden van H. M. de Koningin-Moe-

$\left.{ }^{1}\right) \mathrm{Zie}$,Twee eeuwen Zendingsarbeid in Suriname”, blz. 82. Uitgave v.h. jubileum comité, te verkrijgen Zeist Broederplein 27. 
der; de ouderen in het land drukten het aldus uit: „Ons aller Moeder is heengegaan!', gedachtig hoe onder de regeering van Z. M. Koning Willem III de slaven-emancipatie in 1863 een feit werd.

Tot de slaven is het geweest, dat de eerste zendelingen in 1735 gekomen zijn; onder slaven hebben zij gewerkt, en uit de slaven en hunne nakomelingen is de Protestantsche Christengemeente „De Evangelische Broedergemeente in Suriname" opgebouwd.

Deze Evangelische Broedergemeente is de Protestantsche Volkskerk in Suriname en telt ruim 30.000 leden.

Bij „Zending” denken wij natuurlijk in de eerste plaats aan Evangelie-verkondiging, en dit heeft ook in Suriname vooropgestaan, maar als het goed is, dan zal deze verkondiging altijd gepaard gaan met cultureele en sociale opbouw en daarnaar is ook in Suriname door de Zending gestreefd. Het was op den 7en Augustus 1735, dat de drie eerste zendelingen Hernnhut in Saksen verlieten als verkenners en voortrekkers om te gaan naar „de wilde kust van Guyana", en het was 20 December van dat jaar, toen zij voet aan wal zetten in het toen nog zeer kleine plaatsje Paramaribo. De instructie, die hen was medegegeven luidde: „Bij hun gewone arbeid er op letten of onder de Indianen en Negers iets voor den Heiland te winnen zou zijn". Reeds in 1734 waren door Bisschop Spangenberg, de medearbeider van den graaf von Zinzendorf (de stichter der Evangelische Broedergemeente, 1700-1764), stappen gedaan om de vestiging van Herrnhuter gezinnen in Suriname te bevorderen. De toen nog jonge doctor had hiertoe de noodige besprekingen gehouden met de directeuren van de „Geoctroyeerde Sociëteit van Suriname”. Het resultaat dezer besprekingen was, dat een achttal gezinnen zich in Suriname zouden mogen vestigen; de Sociëteit verstrekte vrije overtocht en zou in Suriname 300 akker land in eigendom afstaan, terwijl de emigranten vrijheid zouden hebben van godsdienstoefening, voor zoover de openbare orde daardoor niet werd verstoord en de kerkelijke autoriteiten daarmede niet werden gehinderd.

Als de eerste drie mannen in Suriname aangekomen zijn, meldt de Gouverneur Mr. Joan Raye aan de directeuren van de Sociëteit: „Ik heb de drie Moravische Broeders naar den Blauwen Berg (bij Bergendal aan de Surinamerivier) gezonden met een van de mijnwerkers, die daar aan 't zoeken zijn naar mineralen'.

Deze eerste poging emigranten uit te zenden mislukte. Reeds na twee maanden was de jongste der drie mannen, von Larisch, aan de gevolgen van het klimaat overleden, en moesten de beide anderen ernstig ziek naar Europa terugkeeren. 
Anderen waren bereid en stonden gereed hunne plaatsen in te nemen, en in 1738 gingen ten tweede male enkele gezinnen naar Suriname, echter om te ondervinden, dat zij van de zijde der regeering niet op de toegezegde hulp, maar op stil verzet tegen hun vestigingsplannen moesten rekenen. En het bleef niet bij stil verzet, maar de houding der Sociëteit veranderde dusdanig, dat alle verdere hulp werd geweigerd. De oorzaak van deze veranderde houding lag in de beschuldigingen, die tegen de Herrnhuters werden geuit; zij zouden schadelijke dwaalleeraars zijn, zoo stond in een „Herderlijke en Vaderlijke Brief” van de Kerkeraad van Amsterdam in 1738.

Echter gaven de „Herrnhuters” het niet op, en door goed en kwaad gerucht heen zijn zij gebleven en nam hun aantal in Suriname toe. Ook als zij ervan beschuldigd worden ,kerk” te houden in hun huis en zij deswege voor den Fiscaal zich moeten verantwoorden. De moeilijkheden, die men de emigranten in den weg legde, de beschuldigingen, die men hun voor de voeten wierp, waren van dien aard, dat er van werkelijke zendingsarbeid geen sprake kon zijn. Daarbij kwam, dat verschillende Broeders en Zusters overleden, en in 1745 had de laatste der zendelingen Suriname verlaten en zich in Berbice (tegenwoordig Britsch-Guyana) gevestigd, om onder de Indianen de zendingsarbeid aan te vangen.

Maar ook na al de eerste teleurstellende pogingen was men in Herrnhut niet ontmoedigd en weer kwamen nieuwe zendelingen; zoo zijn er, totdat wij konden spreken van ,twee eeuwen SurinameZending", ruim 700 mannen en vrouwen uit Europa in Zendingsdienst naar Suriname gegaan.

Van meet af hebben de zendelingen ingezien, dat het van groot belang is, een volk, óók slaven, die men geestelijk en moreel wil opheffen, cultureele en sociale ontwikkeling bij te brengen en reeds in de allereerste jaren begon men met onderwijs. Het behoeft geen betoog, dat dit in den aanvang zeer primitief was. Maar als de Broeders in 1738 het eerste schooltje voor "Christelijk onderwijs" openen, is hiermede de grondslag gelegd voor een arbeid, die van onberekenbare beteekenis is geworden voor de Surinaamsche samenleving, en die van regeeringswege waardeering heeft mogen ondervinden. Het ,Jubileum-Comité" van 1935 zegt hiervan o.a. ${ }^{1}$ ): „Deze arbeid is van onbeschrijfelijke beteekenis voor de Surinaamsche gemeenschap geworden; door den vroegen aanvang en het volhardend doorzetten van dien arbeid, is - zonder tekort te doen aan hetgeen anderen op dit terrein hebben onder-

1) T.a.p. blz. 17. 
nomen en bereikt - zeker de eerste grondslag gelegd voor de ontwikkeling van de Surinaamsche Creolenbevolking en daarmede van den socialen opbouw van het land"'.

De waardeering van regeeringszijde is er echter niet van den aanvang af geweest. Integendeel werd het geven van onderricht aan slaven en hunne kinderen verboden. Dit verbod was nog van kracht in 1848. In dat jaar werd in een circulaire van de hand van den zendeling Otto Tank, gericht „Aan de Heeren Eigenaars en Administrateurs van plantages in de Kolonie Suriname", verzocht in ernstige overweging te willen nemen, wat naar hun meening gedaan kon worden tot verbetering van het lot der slaven en om te verzoeken, dat den zendelingen vrije toegang zou worden verleend om de negers in hunne woningen op te zoeken en aan volwassenen en kinderen onderwijs (desnoods uitsluitend lezen) te geven.

Deze circulaire heeft destijds heel wat beroering teweeg gebracht en de zendelingen, met name de toenmalige praeses Pfenniger, meenden, dat het de slaven niet zou baten, indien te scherpe critiek op de bestaande toestanden werd uitgebracht, waarom hij in zijn antwoord op de, naar aanleiding dezer circulaire hem gestelde, vragen zeer voorzichtig was.

Echter waren de zendelingen niet vergeten, dat reeds in 1760 gouverneur Crommelin er zijn blijdschap over had uitgesproken, dat zij naast de begonnen Indianen-zending, ook onder de Negerslaven wilden werken, en dit doel hebben zij steeds voor oogen gehouden. Bij een inspectie-bezoek in Suriname van zekere Broeder Liebisch werd het punt „onderwijs” ernstig overwogen. In een schrijven van de „Unitäts-Aeltesten-Conferenz” in Herrnhut stond, dat men moest trachten de kinderen van gedoopte slaven, „hetzij dat er nu 6, of 8, 10 of 12 zullen komen, behalve op Zondagen één of twee keer gedurende de week bijeen te roepen om hun onderricht te geven".

Echter heeft het, afgezien van zeer kleine „schooltjes” hier en daar, nog tot 1823 geduurd, eer men van geregeld onderwijs kon spreken. Tot het tot stand komen der Herrnhuterscholen heeft in niet geringe mate bijgedragen de in 1828 opgerichte „Maatschappij tot bevordering van het Godsdienstig onderwijs onder de slaven-bevolking in Suriname". Het was tengevolge van een bezoek van den koninklijken commissaris-generaal J. v. d. Bosch aan West-Indië, dat deze Maatschappij te Paramaribo werd gesticht. In 1829 ontstond in den Haag een tweede afdeeling dezer Maatschappij, die thans nog bestaat.

Als in 1863 de slavernij is afgeschaft, en tien jaren later het 
staatstoezicht over de bevrijde slaven is afgeloopen, breekt een nieuwe tijd aan voor het onderwijs. Reeds bezat de Evangelische Broedergemeente in dien tijd tal van stads- en plantagescholen, en was er zelfs al een begin gemaakt met de opleiding van inheemsche leerkrachten, zoodat in het jaar der emancipatie 20 Surinamers in dienst der 13 Herrnhuterscholen stonden en het aantal leerlingen ruim 1300 telde.

Reeds in 1876 werd de leerplicht ingevoerd en werd de Nederlandsche taal voertaal; De verschillende verordeningen van het Gouvernement brachten aanvankelijk voor het Herrnhuter-onderwijs vele moeilijkheden mede. De eischen, die aan het onderwijzend personeel, aan gebouwen en onderwijs-materiaal werden gesteld leverden vele zorgen op. Langzamerhand kwam er wijziging in de vorm der subsidieering totdat in 1930 - 31 ,gelijkstelling" met het gouvernementsonderwijs werd verkregen. Dat hiermede niet alle moeilijkheden waren opgelost, spreekt vanzelf. In de eerste plaats was er de personeelskwestie en de opleiding. Bovendien moest het zendingsbestuur aan personeel van Herrnhuterscholen, die dus tevens zendingsscholen waren. nog zeer bijzondere eischen stellen. In het Boschland van Suriname werken de Evangelisten als Boschlandonderwijzers.

Bij den aanvang van 1939 waren er 49 Herrnhuterscholen met een totaal van ruim 6000 leerlingen, 1 Eur. Inspecteur van scholen, 2 Eur. leerkrachten, 90 Surinaamsche leerkrachten, 30 Sur. hulpkrachten, terwijl in 17 Fröbelscholen met ongeveer 1200 leerlingen, 35 onderwijzeressen werken en er 14 bewaarscholen zijn, waar hulpkrachten werken. Bij deze scholen zijn een Mulo en een Ulo, 11 gewone lagere scholen, 20 (beperkte) Blo scholen en 16 Boschlandscholen. Welk een groei in betrekkelijk korten tijd!

Zien wij nu op de voortgezette zendingsarbeid dan bemerken wij, dat er omtrent 1820 een groote verandering in de houding der regeering en der officieele (Ned. Herv.) kerk was gekomen. Wel had zich reeds in 1785 een kleine Gemeente in de stad Paramaribo gevormd, die een eigen kerkje bezat, en waren hier en daar op de plantages enkele slaven Christen geworden, maar de tegenstand der autoriteiten was nog niet geweken. Wel had reeds in 1759 gouverneurCrommelin de hulp der Herrnhuter zendelingen ingeroepen om met de Boschnegers te onderhandelen, en konden in 1765 de eerste zendelingen uitvoering geven aan hun wensch om ook in het Boschland aan de z.g. „Wegloopers” het Evangelie te brengen, maar toch duurde het nog lang voor instemming en medewerking werd verkregen. 
Tot deze langzamerhand veranderende houding werkte o.a. mede de bovengenoemde „Haagsche Maatschappij”; ook kwam er geleidelijk eenige waardeering van de zijde der plantageeigenaren en -directeuren, en omtrent 1830 gingen de plantages voor de zendelingen open. Toen kwam de groote kentering. In 1830 hadden de zendelingen toegang tot 11 , in 1863 tot 190 plantages; in 1830 waren er omtrent 2000 gedoopten, in 1863 bijna 19000 , terwijl er in het geheel 27500 in geestelijke bearbeiding waren, en er toen viermaal zooveel zendelingen waren als in 1830. Van het begin af werd er naar gestreefd de gemeenteleden een actief aandeel in het gemeenteleven te laten nemen; allerlei arbeid werd en wordt belangeloos door hen verricht. Vereenigingen tot onderlinge hulp in geval van armoede en ziekte werden opgericht, en tot op den huidigen dag nemen de z.g. „Begis” (letterlijk vert. gebedsvereenigingen) een groote plaats in het gemeenteleven in. In deze tijd is de geheele Creolenbevolking gekerstend en werd de Evangelische Broedergemeente dé Protestantsche Volkskerk in Suriname, die nu op het punt staat van zelfstandigwording.

In een Kerk neemt inwendige zending steeds een groote plaats in en hieronder mogen wij allerlei sociale en cultureele arbeid rekenen.

Zoo werd in 1911 het Kinderhuis Saron opgericht, waar aanvankelijk enkele, later meer, en tegenwoordig een honderdtal Creolenkinderen een onderkomen vinden. Saron is bestemd voor kinderen, die wij hier zouden rekenen onder degenen, die met „lichamelijke of geestelijke ondergang bedreigd worden". Mede door de nawerking der slavernij is het huwelijks- en gezinsleven nog niet overal tot die ontwikkeling gekomen, die men zou wenschen en vele kinderen missen hun natuurlijke verzorger. De moeder is in vele gevallen niet in staat haar kinderen naar behooren alleen te verzorgen, laat staan op te voeden, en zoo voorziet Saron in een dringende behoefte. Saron mag zich verheugen in de belangstelling van velen, terwijl als regel de echtgenoote van de Gouverneur zitting heeft in het Bestuur der inrichting. Saron geniet gouvernementssubsidie en moet dus voldoen aan allerlei eischen. De voeding is zoo doelmatig mogelijk, de huisvesting in vier paviljoens zóó, dat de kinderen niet te veel aan eigen sfeer worden onttrokken maar reinheid en orde leeren. De „huisouders” zijn Europeesche zendingsarbeiders; als hulpkrachten werken er drie Surinaamsche zusters en een Surinaamsche opzichter. De kinderen bezoeken de Herrhuterschool; de meisjes worden bekwaamd in huishoudelijke bedrijven, terwijl de jongens zoo mogelijk een vak leeren, maar meestal aan tuin-, la ndarbeid en vee- 
teelt doen. $\mathrm{Zij}$ worden in de gelegenheid gesteld zich, wanneer zij de leeftijd bereikt hebben, waarop zij de inrichting moeten verlaten, in de nabijheid van Saron te vestigen als klein-landbouwer en genieten dan nog hulp en leiding der inrichting.

Al gaat Bethesda niet direct uit van de Evangelische Broedergemeente, zoo mogen wij in deze bladzijden de Protestantsche $\mathrm{Me}$ laatschen inrichting niet overslaan, daar haar geschiedenis nauw is samengeweven met die der zending, en plm. 90\% der zieken „Herrnhuters" zijn. Bovendien was en is de Directeur een der zendelingen der Evangelische Broedergemeente en werken er Herrnhuter Diaconessen. Bethesda is een belangrijk stuk in de inwendige zending en Christelijke barmhartigheid. In 1896 opgericht, gelegen op eenige uren afstands van de stad aan de Surinamerivier, werd zij in 1933 verplaatst in de nabijheid van de stad. Haar wit geschilderde paviljoens met de roode daken liggen daar zoo vriendelijk tusschen het groen, en de vreemdeling vermoedt niet de wereld van lijden, die daarachter schuilt. Ruim 170 melaatschen vinden hier een liefderijke verpleging en een thuis. In het Kinderhuis zijn ruim 90 kinderen: de volwassenen hebben elk hun eigen kamertjes. Naast verbinden en verplegen is er op te voeden en te onderwijzen, is er troost te brengen in nameloos lijden, en kan hier het Evangelie verkondigd worden aan hen, voor wie deze Blijde Boodschap nog een zeer bijzondere beteekenis heeft.

Ten slotte noemen wij als tak van inwendige zending de Stadszending. Wij noemen deze niet het laatst, omdat zij minder belangrijk zou zijn dan de anderen, integendeel, maar omdat wij over dit stuk arbeid gaarne iets uitvoeriger willen zijn, en omdat schrijfster er gedurende bijna zeven jaren heeft mogen medearbeiden.

Het is dit jaar 25 jaren geleden, dat de Stadszending werd opgericht. Zij heeft een tweeledig doel, n.l. een geestelijk en een maatschappelijk. Deze beiden zijn eigenlijk niet te scheiden; zij gaan hand aan hand. Wanneer de Stadszendings-arbeidsbeurs tracht werkeloozen arbeid te verschaffen, mogen en moeten deze menschen iets ervaren van de geest, waarin wij hen willen helpen. Daar melden zich jonge mannen, 't laatste jaar lieten zich 72 inschrijven, waarvan wij helaas slechts 13 aan werk konden helpen, maar ook de 59 anderen mochten ervaren: hier zijn menschen, die zich om ons bekommeren. Vijf jaren geleden werd begonnen met vestiging van klein-landbowwers op een ons door het Gouvernement ter beschikking gesteld terrein; de Stadszending kreeg de leiding en het beheer, en al werd tengevolge van allerlei factoren 
juist het laatste jaar dit toezicht beëindigd, in menig opzicht blijft deze nederzetting met de Stadszending verbonden.

Daar worden in de Stadszending naai- en handwerkcursussen gegeven; in de morgenuren voor meisjes, die de school verlaten hebben, en des avonds voor haar, die overdag haar werk hebben.

Op Zondagmiddagen hebben wij onze kindersamenkomsten, geregeld door een paar honderd kinderen bijgewoond, waar meestal aan de hand van lichtbeelden (sprookjes, natuurtafereelen en Bijbelsche platen) wordt verteld.

Daar is onze Evangelische Film en Lichtbeeldendienst. In de stad en in districtsplaatsen worden avonden gehouden ter ontspanning en opbouw. Het is van veel waarde voor de bewoners van afgelegen districtsgemeenten, wanneer wij nu en dan een avond, soms een paar dagen, komen. Overdag wordt huisbezoek gedaan; valt er een Zondag in, dan wordt een Godsdienstoefening gehouden, anders des avonds een Evangelisatiesamenkomst, soms met lichtbeelden. Er worden een of meer filmavonden georganiseerd, waartoe wij ons enkele jaren geleden een klank-smalfilm-toestel aanschaften, dat met een kleine motor ook op plaatsen, waar geen electrisch licht is, gebruikt kan worden. Met onze films bezoeken wij ook de Protestantsche en de Gouvernements-melaatscheninrichtingen. Welk een bijzondere beteekenis zulk een bezoek juist dààr heeft, kan men zich ter nauwernood voorstellen. Welk een vreugde, als wij dààr komen, waar zooveel geleden wordt, en wij daar een feestelijke avond houden kunnen. Hoe juichen de kinderen in Bethesda en hoe verheugd zijn de volwassenen, als kinderen zoo blij! De moeilijkheid is om steeds nieuwe en geschikte films te krijgen, en wij zijn dankbaar, als men ons helpt met kleine of grootere bijdragen om normaalfilms te huren of smalfilms te koopen en de verdere onkosten te dekken. Zulk geld is goed besteed! Op Groot Chatillon, het Gouvernements melaatschen asyl, dat ver van de stad ligt, knoopen wij aan zulk een bezoek zoo mogelijk een Evangelisatiesamenkomst voor de Protestantsche zieken en bezoeken wij onze Gemeenteleden zooveel mogelijk in hun kamers. Ook juist deze bezoeken worden zeer gewaardeerd. Een dergelijke tocht geeft dagen lang vreugde en afleiding in het dikwijls eentonig leven der zieken, en wie hiervan ooggetuige zou zijn, zou zeker dit mooie werk willen steunen.

In onze Stadszendingszaal zelf houden wij ook geregeld z.g. Familieavonden, met film of lichtbeelden; goede ontspanning willen wij hierdoor aan velen verschaffen.

De voornaamste tak van arbeid van de Stadszending is het 
Evangelisatiewerk. Maandelijks wordt er een Evangelisatieavond gehouden, voorafgegaan door een georganiseerde uitnoodigingsdienst. Stelselmatig gaan wij daarbij de geheele stad door, elke maand een of twee straten, om bij huisbezoek onze uitnoodigingen af te geven in de vorm van een courantje, terwijl in de week na de Evangelisatiesamenkomst, zoover de tijd het toelaat, dezelfde gezinnen nog eens worden bezocht. Het vaak persoonlijk contact, op deze wijze verkregen is van groot belang. De geestelijke en maatschappelijke nooden waarmede men in aanraking komt, zijn vaak bitter groot. Hierin wil ook de in de Stadszending gevestigde Centrale Armenzorg der Evangelische Broedergemeente tegemoet komen. Steun verleenen is altijd een moeilijk werk en vooral als de behoeftigen velen en het geld weinig is. In de meeste gevallen kunnen wij gezinnen ten hoogste met $f$ 2.-, alleen wonende personen met $f 1$.- per maand, helpen. Immers onze gemeenten zijn zelf arm, en er wordt veel van hen gevraagd, zoodat de inkomsten van onze Armenzorg niet groot zijn. Maar deze kleine steun beteekent in de meeste gevallen toch reeds een heele tegemoetkoming en wij ondervinden roerende dankbaarheid. Toch zouden wij zoo gaarne veel meer afdoende kunnen helpen. In vele gevallen worden ook versterkende middelen verstrekt en dekking en kleeding. Tot dit laatste stelt de Vereeniging tot bevordering van het Onderwijs ons mede in staat; per jaar kunnen wij aan een 3 à 400 kinderen schoolkleeding uitreiken, terwijl dit tevens een kleine werkverschaffing is voor werkelooze naaisters en kleermakers.

De Armenzorg stelt ons echter ook in ander opzicht voor groote moeilijkheden. Wie moet geholpen worden ? Waar is hulp het meest op zijn plaats? De steun wordt door ons aan huis bezorgd en zoo komen wij geregeld met de daarbij betrokken personen in aanraking, maar dan juist vragen wij ons dikwijls af, of wij mogen helpen als de verantwoordelijke persoon, de echtgenoot en de vader, zich niets van de zijnen aantrekt. In vele gevallen staat de moeder alleen voor de verzorging der kinderen; soms is de man het grootste deel van het jaar in bosch- of goudbedrijf, en geld ziet de vrouw dan meestal niet. In andere gevallen onttrekt hij zich geheel van de verantwoording, die op hem rust, en vaak is hij werkeloos. De moeder tracht in de nooden van het gezin te voorzien, maar bij gebrek aan werk blijft er voor haar niet veel anders over dan "kleeren wasschen”, en het stereotype antwoord op onze vraag waarvan zij leeft, is: „Van een banknoot (halve gulden) kleeren wasschen per week". Men zegt wel eens, dat er in 
Suriname niemand van honger sterft - dat moge zoo wezen, maar er zijn heel wat menschen en kinderen die ondervoed zijn; dat zien wij maar al te veel, die dagelijks met de armsten in aanraking komen.

Keeren wij nu tot de Stadszending zelf terug, dan bezoeken wij nog onze Leeskamer, die steeds goed bezocht wordt. Hoe dankbaar zijn wij, wanneer men ons gedenkt met goede tijdschriften en periodieken. En dan onze Bibliotheken voor kinderen en volwassenen. Het is ons niet mogelijk geregeld goede boeken aan te schaffen en toch is aanvulling telkens gewenscht, zoodat wij zeer dankbaar zijn voor goede Hollandsche lectuur. In de Stadszending worden voorts Bijbelkringen gehouden, voor meisjes en dames. Daar bevindt zich de verkoop-centrale van Bijbels en allerlei lectuur voor catechisaties, zondagscholen en particulieren. Daar is ook de administratie en het toezicht op de Weesvoogdij der Evangelische Broedergemeente, waarbij vele vrijwillige krachten helpen als huisbezoeksters. Daar is het kantoor van het Zieken en begrafenisfonds der Evangelische Broedergemeente. Het z.g. "Jubileumfonds". Deze en nog tal van andere werkzaamheden worden in de Stadszending verricht; zij is in de Protestantsche samenleving van onze kolonie een belangrijke factor geworden, en ondervindt ook veler belangstelling. $Z_{\mathrm{ij}}$ moet zichzelf bedruipen, hetgeen lang niet altijd gemakkelijk is.

Thans nog iets over het Jeugdwerk, aan het hoofd waarvan een Surinamer als jeugdleider staat. Naast speciale kerkelijke jeugddiensten des Zondags wordt aan Chr. Padvinderij gedaan, jeugddagen en conferenties worden belegd, die meestal met de Pinksterdagen hun hoogtepunt hebben.

Voor de meisjes is er, naast allerlei meisjesvereenigingen, het Driehoekwerk of S. M. C. (Sur. meisjesclubs), aangesloten bij het Ned. Driehoekwerk (N. M. C.). Ruim 400 meisjes zijn hierbij aangesloten met 20 leidsters en hulpleidsters, waarvan alleen de hoofdleidster (groepleidster) een Europeesche is.

Dit jeugdwerk is van groot belang en er zijn nog vele mogelijkheden; het wil de jongens en meisjes maatschappelijk en geestelijk bijstaan en hen helpen om straks als bruikbare burgers hun leven als Christenen te leven.

Hiermede hebben wij onze rondgang door de Creolenkerk beeindigd, maar er valt nog veel te vertellen. Allereerst over de arbeid onder de plm. 20.000 Boschnegers.

Van meet af hebben de zendelingen getracht ook de z.g. Wegloopers, de Marrons, te bereiken. De naam Boschneger geldt allen, 
die, van Afrikaansche afkomst, de binnenlanden van Suriname bevolken. $\mathrm{Zij}$ zijn alleen bereikbaar langs de geweldige rivieren, over de watervallen en stroomversnellingen; zij hebben hun dorpen, waarin zij wonen in hutten, als weleer in Afrika, in de onmetelijke, schier ondoordringbare oerwouden. Eerst in 1765 verkregen de zendelingen vaste voet onder dit uit zeer verschillende stammen bestaande volk. Eén ding hadden zij gemeen, zij waren allen Animisten. De medische nood is hier minstens even groot als de geestelijke nood. Vele blanke zendelingen hebben jaren lang in het binnenland gewerkt en werden opgevolgd door Surinaamsche Evangelisten, die daar nu op een 14-tal posten aan de verschillende rivieren arbeiden, als Evangelist-onderwijzer-ziekenoppasser. Enkelen kregen een speciale medische opleiding in de stad en dit is wel zeer noodig. Schrikbarend groot is het aantal zieken, daar in de binnenlanden. Lepra, syphilis, framboesia, tuberculose, richten verwoestingen aan, en ook andere ziekten. Geen hulp voor hen, die een ongeluk overkomt, geen hulp voor vrouwen in barensnood, ja ook geen hulp bij doodgewone maar afschuwelijke kiespijn! Zóó was het tot voor enkele jaren, zóó is het nog in heele streken! Onze Evangelisten doen wat zij kunnen, maar er is meer noodig en er begint hulp te dagen! Ruim vier jaren geleden vestigde zich de eerste Nederlandsche Zendingszuster in Gansee aan de Boven-Suriname; zij leeft daar als eenige blanke temidden der Boschnegers, zij is verpleegster en vroedvrouw, en moet noodgedwongen dagelijks als arts optreden. Binnen enkele maanden zal zij worden bijgestaan door een tweede zuster; samen zullen deze beide vrouwen daar in heel veel nood en lijden verlichting, zoo mogelijk genezing, mogen brengen. De Vereeniging SIMAVI was ons hierbij van groote geldelijken steun, maar.... er is meer noodig. Dringend noodig is een hospitaal. ' $t$ Kan en 't mag niet langer uitblijven. SIMAVI heeft een bedrag toegezegd, maar dit is niet genoeg. Ik schreef eens in een artikel: „Wij hebben in Suriname géén Albert Schweitzer, maar wij hebben wel duizenden van lijdende Boschnegers”. Thans kan ik er aan toevoegen: „Wij hebben twee zusters, maar.... geen hospitaal, geen dokter.... mag dit zoo blijven?" Het moet anders worden en het kan anders worden, indien Nederland, gij en ik, ons niet van deze noodzaak afmaken. Erishier een prachtig stuk werk te verrichten. Het hospitaal moet er komen, liefst nog dit jaar. De zending kan dit niet bekostigen; zij zorgt voor dokter en zusters; die zijn er of staan bereid om te gaan, de middelen om hen te zenden of te onderhouden, het hospitaaltje.... dààr moeten anderen voor zorgen.... 
En nu nog een woord over de Nieuwere zending. Daaronder verstaan wij de arbeid onder de Aziaten, Britsch-Indiers en Javanen, die als contractarbeiders naar Suriname kwamen en veelal na afloop van hun contract gebleven zijn. Thans wonen er ongeveer 40.000 Britsch-Indiërs en 34000 Javanen in Suriname. De Evangelische Broedergemeente begon de zendingsarbeid onder de eersten in 1901, thans werken er 2 Eur. zendelingen, 2 Eur. zusters en 5 Britsch-Indische Evangelisten. In een kinderhuis worden een 50-tal kinderen opgevoed. Allerminst wordt hier dwang uitgeoefend om tot het Christendom over te gaan; dit kan alleen op eigen verzoek uit vrije keus of op verzoek der ouders geschieden; wel wordt ernaar gestreefd het heillooze kinderhuwelijk tegen te gaan en menige jongen en meisje mocht in het Kinderhuis Alkmaar een nieuwe blik op het leven krijgen en velen vonden er zeker ook vrede in het Evangelie. In de stad zoowel als in de districten heeft de zending speciale schooltjes voor Britsch-Indische kinderen.

Ook onder de Javanen werd het zendingswerk aangevat en wel in 1909. Ook daar eigen schooltjes, een eigen Kinderhuis Leliendaal met pl.m 40 kinderen, twee Eur. zendelingen, 1 Eur. zuster en 6 Javaansche goeroes.

Onder deze beide bevolkingsgroepen groeit het werk langzaam maar gestadig; zooveel mogelijk is van den aanvang af gestreefd naar zelf-onderhoud en zelf-uitbreiding, zoodat het straks ook worden kan zelf-bestuur.

Er liggen hier bergen van werk, bergen van moeilijkheden, maar die zijn er om ze te overwinnen!

Wij zijn aan het eind van ons overzicht gekomen en hebben getracht in de ons toebedeelde plaatsruimte, $U$ iets te beschrijven van de geestelijke, cultureele en maatschappelijke beteekenis van het werk der Herrnhuterzending. Sedert 1927 is het werk geheel in handen van het Zeister Zendingsgenootschap, dat dus de geestelijke en stoffelijke verantwoording draagt. Jaarlijksch is een som van ruim $f 100.000$ noodig. De Kerk in Suriname brengt reeds een belangrijk bedrag op, maar de Suriname Zending, het geestelijk en maatschappelijk werk, kan de belangstelling en offervaardigheid uit Nederland nog niet missen. Moge ook dit artikel ertoe bijdragen die belangstelling te wekken of te verlevendigen. Februari 1939. 